staff were each vital to the success of my 2-year academic contract and to my doctoral studies - as was the support of religious institutions.

International psychiatry remains at the heart of the College raison d'etre. There are over 3000 Members and Fellows outside the UK, and over $30 \%$ of the consultant and training posts in the NHS are filled by graduates from non-UK medical schools. Three of the eight members of the current executive of the World Psychiatric Association (WPA) are distinguished College Fellows. Interestingly, in recently published books two other British-based international South Asian psychiatrists (Channi Kumar and Suman Fernando) are honoured, both of whom influenced me considerably, and both of whom were 'movers and shakers' of UK mental health services as well as of College opinion (Cox, 2014; Pariante et al, 2014).

International readers of this journal will of course draw their own conclusions from these three papers about the pros and cons of partnership arrangements. They remind me of the need for a strong international College board to focus on this vital international work, to support bilateral exchanges and to develop further its own initiatives, including the Volunteer Scheme, and to encourage and resource the International Divisions.

Hamid Ghodse, the founding Editor of this journal and founding chair of the board, was a brilliant ambassador for the College. The current WPA leadership, with a College past President as WPA President, provides a landmark that should help to reduce any tendency towards isolationism in British psychiatry, or a reluctance to recognise that multicultural, multifaith Britain benefits from a multicultural, multifaith mental health workforce. Opportunity for the College (one of the largest member societies of the WPA) to fulfil some of its international commitments within this umbrella, including the monitoring of ethical practice, is another consideration at the present time.

Perhaps BJPsych International, in its new format, can become even more of a forum for this renewed commitment to global psychiatry and particularly for assisting and motivating psychiatrists to work 'outside the box' and for a short or more prolonged period to work outside the NHS.

The three papers are a reminder that for psychiatrists planning to work abroad, transcultural psychiatry is 'good psychiatry', but this is so only if good psychiatry is, at its core, interpersonal and conceptually complex.

\section{References}

Cox, J .L . (2014) Suman Fernando's contribution to British psychiatry. In Critical Psychiatry and Mental Health: Exploring the Work of Suman Fernando in Clinical Practice (eds R. Moodley \& M. Ocampo), pp. 248-252. Routledge.

Pariante, C. Conroy, S., Dazzan, P., et al (eds) (2014) Perinatal Psychiatry: The Legacy of Channi Kumar. Oxford University Press.

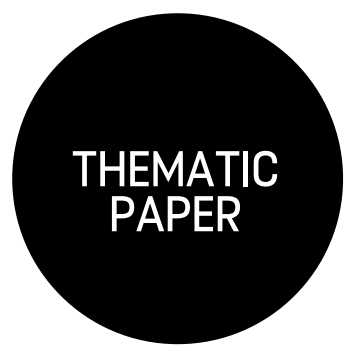

\title{
Sustaining international careers: a peer group for psychiatrists working in global mental health
}

\author{
Julian Eaton, ${ }^{1}$ Nick Bouras, ${ }^{2}$ Lynne Jones, ${ }^{3}$ Charlotte Hanlon, ${ }^{4}$ Rob Stewart ${ }^{5}$ \\ and Vikram Patel ${ }^{6}$
}

${ }^{1}$ Mental Health Advisor, CBM International, Togo, email julian. eaton@cbm.org

2Professor Emeritus, King's College London, Institute of Psychiatry, Psychology and Neuroscience, London, UK

Neuroscience, London, UK Foundation Trust, UK

${ }^{4}$ Associate Professor, Addis Ababa University, Ethiopia

${ }^{5}$ Consultant Psychiatrist, UK

${ }^{6}$ Professor, London School of Hygiene and Tropical Medicine, UK; Sangath; and Public Health Foundation of India
Regular appraisal and revalidation are now a routine part of professional life for doctors in the UK. For British-trained psychiatrists working abroad (in either development/humanitarian or academic fields) this is a cause of insecurity, as most of the processes of revalidation are tailored to those working in the standard structures of the National Health Service. This article explores the degree to which a peer group for psychiatrists working abroad has achieved its aim of helping its members to fulfil their revalidation requirements. It gives recommendations for how those considering work abroad can maximise their chances of remaining recognised under the revalidation system.
Meeting the expectation for doctors to maintain their level of knowledge and clinical skills has become a routine part of professional medical life in the UK. Since 2012, the processes for appraisal and revalidation have been integrated into the work environment of hospitals and other medical work spaces in the UK, but this poses a problem for doctors not following standard careers within the National Health Service (NHS). Although there are some mechanisms for doctors without a designated professional body, for those who have chosen to live and work abroad, revalidation remains a significant challenge and can make returning to work in the UK bureaucratically difficult.

One group facing this problem are those who work in global mental health, either in the development/humanitarian field or in academic 
The authors and members of the peer group gratefully acknowledge the ongoing support of Maudsley international and the south yHS Foundation Trust, under the Support Personal Developmen Scheme (SPDS), in particular Dr Ranga Rao and Dr Michael Holland. The authors would like to thank all those who completed the survey. institutions. In 2008, a group of psychiatrists who had received their specialty training in the UK (Members or Fellows of the Royal College of Psychiatrists) but were now working predominantly abroad established a peer group similar to those British-based doctors use for the purposes of continuing professional development (CPD). Peer supervision is a key tool in appraisal and revalidation, allowing mutual learning and evaluation, and the setting of common standards. This article reflects on how successful this group has been in supporting CPD and revalidation.

\section{The group's aims and development}

The aims of the group are:

- to provide an opportunity to share clinical and professional experience and knowledge on a regular basis

- for its members to remain updated with respect to CPD in the UK

- to fulfil the requirements for maintaining registration and revalidation.

When the peer group was started, the processes of registration and revalidation were themselves in development and the group hoped to provide a model for doctors overseas seeking to maintain professional recognition in the UK. In this process of exploring (and sometimes negotiating) how this could be done, the group has relied on the support of the South London and Maudsley (SLaM) NHS Foundation Trust in terms of facilitating links with the Royal College of Psychiatrists and the General Medical Council (GMC), and offering honorary appointments to those participating in the group, something that is essential in order to have an institutional framework for revalidation. Maudsley International, an organisation affiliated to SLaM, which aims to improve global mental health by sharing expertise, has hosted and helped coordinate the group since its inception.

Over the past 6 years, the group has convened every 3-4 months via Skype. The meetings, chaired on a rotating basis, aim to provide a forum for discussions around the discipline of global mental health, clinical case studies, and updates on registration and revalidation issues. Members also review each other's personal development plans and other evidence of maintenance of clinical skills. This has proved to be a challenge, as these requirements have changed with time, and it was necessary to communicate regularly with the regulatory bodies in the UK to ensure the correct standards were being followed. On occasions it was clear that there was no guidance available for those not in the standard revalidation process. Within these regular meetings, a supportive network naturally developed where advice was shared about a wider variety of issues than those in the original aims of the group.

\section{Survey of group members}

In the context of increasing interest in pursuing international careers in mental health, we decided to examine how well the peer group had fulfilled its initial aims. One of the main reasons why people might choose not to do international work is the risk of making a subsequent British medical career difficult. Documenting successful mechanisms for maintaining registration and validation in the UK would go some way to assuage these anxieties. We therefore circulated a questionnaire to group members to explore whether this had been achieved. The questionnaire (available online) was sent to all members. This is a small group and complex statistical or independent thematic analysis was not appropriate. Open narrative responses are reported here.

We also asked three senior psychiatrists in the UK who have supported the process (members of Maudsley International and SLaM) about their views and experiences, using a modified version of the same questionnaire.

\section{Results}

At the time of the survey, the group had eight members, seven of whom completed the questionnaire (Table 1). In addition, all three supporters responded.

\section{Participation in and benefits of the group}

Commitment and participation have been high. All but two of the respondents said that they had attended 'all' or 'almost all' of the meetings (the other two responded 'over 50\%'). There was a consensus that the main aims of the group had been met. The only weak element was that members'

Table 1

Summary of peer group membership and characteristics of respondents

\begin{tabular}{|l|l|l|}
\hline & Total group $(n=8)$ & Survey respondents $(n=7)$ \\
\hline Female:male ratio & $3: 5$ & $3: 4$ \\
\hline Type of work $^{\text {a }}$ & $\begin{array}{l}\text { International development: } 2 \\
\text { Humanitarian: 1 } \\
\text { Research/academic: } 5\end{array}$ & $\begin{array}{l}\text { International development: } 3 \\
\text { Research/academic: } 4\end{array}$ \\
\hline Countries where members work & & Australia, Ethiopia, India (x2), Malawi, Togo, UK \\
\hline Conflict and disaster zones & Australia, Ethiopia, India (x2), Malawi, Sri Lanka, Togo, UK & Various \\
\hline
\end{tabular}

There is considerable overlap between research and implementation in global mental health, with most people doing a mix of both.

bome members work in jobs that take them to many low-income countries, and two had recently returned to the UK but remained involved in international work. One member mainly worked on a short-term voluntary basis. 
registration was not recognised as fully equivalent to that of colleagues in the UK, something beyond the control of the group. Common themes were a sense of support from a community of practice with shared experiences, mutual learning on issues related to global mental health, and advice and guidance for what are relatively unusual, but shared, career paths.

One member commented:

[the group members] give me a network in which to bring up challenges of international work ... [and] helped me feel validated and supported regarding [an] unusual career track.

One member who has subsequently returned to work in the UK found the fact that being able to show even this level of CPD and revalidation while abroad helped the transition back to professional life in the UK. Continued membership of the group by those now in the UK is an open question, with several choosing to continue to participate due to their interest in the field.

Members occasionally met each other in person, by chance, as part of their shared global mental health work, which served to strengthen the group.

\section{Challenges}

Survey responses indicated that there were three main challenges to the running of the group.

- The members of the peer group have very demanding jobs, with many of them travelling extensively for work. This, coupled with living in different time zones, made it difficult to find time to meet as often as would have been ideal. For example, extra meetings were needed to accommodate the number of clinical case reviews that is recommended for revalidation.

- The Skype platform, while ubiquitous and free, was not ideal for some settings where members lived (particularly sub-Saharan Africa). Online communication through platforms like Skype is illegal in some countries. Some individual members often dropped in and out of meetings due to poor internet connections.

- The group members clearly did not fit in with standard procedures established for UKbased doctors. For example, it was not clear what qualified as CPD and how this should be documented, how reappraisal could be done in an isolated low-income setting, or who should supervise revalidation. Advice and consensus helped overcome these uncertainties. Support from SLaM and Maudsley International allowed the fulfilment of some requirements, like senior colleague support for revalidation, that would not otherwise have been possible. This external reality has meant that while most members have been able to fulfil their revalidation needs to a far greater extent than if the group had not existed, there will continue to be challenges to having international careers recognised in the UK.

\section{Comments from senior supporters of the group in the UK}

The three supporters felt that they had learnt about the different experiences of working in the international and development settings in which members were based. They also all recognised and appreciated the support group members offered each other. One felt that, given the extensive research being carried out by the members, it would be useful to spend time reviewing recent publications related to global mental health.

One supporter said:

It has raised my awareness of the practical, professional and clinical issues faced by colleagues working in the developing world.

\section{Conclusion}

Overall, the survey showed that a peer group can provide a valuable network, allowing the members to share and strengthen knowledge and expertise despite being geographically isolated. While there is some way to go, the group has proved to be one mechanism through which those choosing careers in global mental health can maintain professional recognition in the UK. For those considering working abroad, some simple steps may ease reentry into work in a home country. These include:

- maintaining affiliation with medical registration bodies (the GMC in the UK) and ensuring proper registration in any host countries

- engaging with an institution to sponsor and provide a framework for CPD (in our case SLaM NHS Trust)

- following accredited CPD learning opportunities online (such as those provided by the Royal College of Psychiatrists)

- participating in peer-supported learning networks.

Advances in technology, including internetbased models of distance learning, can be adopted by professional groups for peer support and training, such as this peer group of psychiatrists working in global mental health.

BJPsych International's online presence

$$
\text { Blog }
$$

http://www.BJPsychInternationalblog.org

\section{Facebook}

https://www.facebook.com/

BJPsychInternational

Twitter

@ BJPsychInt 